\title{
Chemotaxis of fruit fly species against Methyl eugenol in the presence of different food flavours in a guava orchard
}

Mansoor Ahmed Chajro ${ }^{1}$, Fahad Nazir Khoso ${ }^{1 *}$, Imran Khatri ${ }^{1}$, Jamal u Din Hajano ${ }^{2}$, Abdul Mubeen Lodhi ${ }^{3}$, Sohail Otho ${ }^{1}$, Imtiaz Ahmed Nizamani ${ }^{3}$, Munir Ahmed ${ }^{4}$ and Anser $\mathrm{Ali}^{5}$

1. Department of Entomology, Faculty of Crop Protection, Sindh Agriculture University Tandojam-Pakistan

2. Department of Plant Pathology, Faculty of Crop Protection, Sindh Agriculture University Tandojam-Pakistan

3. Department of Plant protection, Faculty of Crop Protection, Sindh Agriculture University, Tandojam-Pakistan

4. School of Biological Sciences, University of the Punjab, Quaid-e- Azam Campus Lahore, Pakistan

5. Department of Zoology, Mirpur University of Science and Technology, Azad Jammu Kashmir-Pakistan

*Corresponding author's email: fnkhoso@sau.edu.pk ; fahadjamani@gmail.com

Citation

Mansoor Ahmed Chajro, Fahad Nazir Khoso, Imran Khatri, Jamal u Din Hajano, Abdul Mubeen Lodhi, Sohail Otho, Imtiaz Ahmed Nizamani, Munir Ahmed and Anser Ali. Chemotaxis of fruit fly species against Methyl eugenol in the presence of different food flavours in a guava orchard. Pure and Applied Biology. Vol. 8, Issue 1, pp452-459. http://dx.doi.org/10.19045/bspab.2018.700204

\begin{tabular}{llll}
\hline \hline Received: 07/09/2018 & Revised: 26/11/2018 & Accepted: 06/12/2018 & Online First: 12/12/2018 \\
\hline \hline
\end{tabular}

\section{Abstract}

Male annihilation technique has been successfully used against fruit flies. Number of experiments has been performed to improve this technique for more effective results. Similarly, in this study, different food additives were used in methyl eugenol traps to improve the attraction of the lure. A Randomized Complete Block Design experiment was designed and conducted at guava orchard in Agriculture Research Institute Tando Jam during the 2017 season. In each treatment, two wicks were used simultaneously, whereby one wick of methyl eugenol (ME 4ml/wick) contained $85 \%$ methyl eugenol, $10 \%$ sugar and $5 \%$ insecticide and the other $4 \mathrm{ml} /$ wick contained different food essences. The treatment were; T1 (ME+ lemon essence), T2 (ME + Mango essence), T3 (ME + Vanilla), T4 (ME + Orange essences) and T5 was used as control with only ME solution. Each treatment had four replications. Two Tephritid species; Bactrocera zonata and B. dorsalis were captured. The maximum mean number of $B$. zonata recorded was for T1 (312.72 \pm 4.39$)$, while the minimum number of flies was captured in T5 (225.39 \pm 4.47$)$. The results revealed that, the highest mean numbers of B. zonata $(238.81 \pm 11.39)$ was in April while the minimum population was obtained in January (3.23 \pm 0.41$)$. High significant difference $(p<0.001)$ was recorded between treatments. Maximum number of B. dorsalis was collected in T1 (30.98 \pm 1.94$)$, whereas; minimum number of flies was captured in T4 (17.62 \pm 1.64$)$ and it reached its highest number in April (15.1 \pm 0.10$)$. Positive correlation was reported between all treatments and temperature while it was negative with relative humidity.

Keywords: Bactrocera dorsalis; Bactrocera zonata; Food essences; Guava; MAT

\section{Introduction}

The guava fruit (Psidium guajava) is locally

known as Zeetone/Amrood, belongs to family Myrtaceae. The production area of guava in Pakistan is about 62.5 thousand hectares with annual production of 421.3 
thousand tones $[1,2]$. The plant is cultivated for its delicious fruit [3]. The size, shape, and flavour largely depend on the climatic conditions and variety [4]. The bearing of fruit is observed twice per annum, but the best quality is obtained in winter [5]. The fruit is mostly eaten in its fresh form, but other products such as jams, juices, sauces, salad and puddings are also prepared [6]. Besides all these, the guava fruit also contains carbohydrates $(11 \%)$, protein $(0.7 \%)$ and a significant portion of vitamin A, B1, B2 and C and some minerals [7].

Furthermore, different parts of the guava plant are used for the treatment of gastrointestinal disorders, for curing the ulcers, wounds, boils, cuts, infectious site and rheumatic sites [8]. Moreover, the fruit is used as medicine for the treatment of bleeding gums and malaria $[9,10]$. In some countries, it is used to cure acute diarrhoea, flatulence, gastric pain, cough, pulmonary diseases $[9,11]$.

Despite great importance, the guava cultivation in Pakistan is reducing every year. There are many reasons for the reduction in cultivation, among which are decline in yield due to insect pests which damages both plant and fruit. The insects causing loses to guava reported from Pakistan are; fruit flies, Mealy bug, False spider mite, Green stink bug, Redbanded thrips, Guava fruit moths, Guava whitefly and Scale species [12]. Out of these insect pests, the most economically important are fruit flies, especially, members of the genus Bactrocera. The genus consist of about 651 known species with 50 species considered to be highly damaging $[13,14]$. Fruit flies attack a wide range of fruits and vegetables throughout the world causing losses in quantitative and qualitative terms [15]. In Pakistan, the severity of damage is reported from 5 to $100 \%$ [16].

To control fruit fly species, different management tools such as cultural practices, mechanical, biological, chemical, and physical control, have been implemented.
Largely, farmers rely on synthetic insecticides including Dipterex, Imidacloprid, Triazophos for controlling these flies [17-20]. The intensive use of insecticides has created great concern for the general public, and the effectiveness is also limited [21]. In the recent past, the alternative method of male annihilation technique is being used successfully against some Bactrocera species [22]. This technique is environmentally safe, and it comprises a kill station containing lure (methyl eugenol) to attract the fruit flies and insecticides to kill them [23]. Currently, some experiments were conducted by the researchers to improve the efficacy of baits by adding some synthetic compounds [24, 25]. Recently, Ullah et al. [26] used different food essences with methyl eugenol (ME) baited and Cue Lure (CL) baited traps. The results of the study proved that addition of essences significantly increases the attraction of baits against fruit flies as compared to control. In regards to the promising results from the previously published literature, this study was suggested to evaluate the performance of male annihilation technique against two fruit fly species in a guava orchard after impregnating lures with different food flavours.

\section{Materials and methods}

\section{Study site}

The experiment was conducted at Guava orchard (Larkano cultivar) farm in Agriculture Research Institute (ARI) Tando Jam at, Sindh, Pakistan from January to April 2017.

\section{Experimental design and replications}

Experiment was laid out in Randomized Complete Block Design (RCBD) with five treatments and each treatment was replicated four times. These traps were placed on an equal height of 6 feet and separated by $12 \mathrm{~m}$ following Bugti et al. [27]. All the selected trees were of same age at fruiting stage.

\section{Pheromone traps and treatments}

Twenty Steiner traps $(36 \times 11 \times 16 \mathrm{~cm})$ were used in this experiment. Each trap contained 
two wicks of cotton, one with traditional Methyl eugenol solution (4ml) comprised of Methyl eugenol (85\%) sugar (10\%) and Malathion insecticide (5\%) and the second wick was impregnated with $4 \mathrm{ml}$ of essence; lemon essence (T1), mango essence (T2), vanilla essence (T3), orange essence (T4) while the control treatment (T5) has only water in second wick. The cotton wicks were changed after 15 days interval.

\section{Data collection and analysis}

The data on the captured fruit flies was recorded weekly and flies were counted and grouped depending on morphological characters published by Prabhakar et al. [28]. The metrological data was obtained from the Metrological Section, ARI Tando Jam, Sindh, Pakistan. The statistical analysis was performed through JMP 9.1 Software. Analysis of variance (ANOVA) was performed to calculate means and standard error. The Least Significant Difference was run to obtain grouping between the treatments. For assessing correlation between collected flies and biotic factors, Pearson correlation coefficient was performed.

\section{Results and discussion}

During the study period, two species of fruit flies (males) were identified. The species were; Bacterocera zonata and B. dorsalis. The morphological characters were in line with work published previously [28]. The data collected (Table 1) on the population of $B$. zonata and $B$. dorsalis revealed that the highest grand mean populations of $B$. zonata and $B$. dorsalis was $(238.81 \pm 11.39)$ and (15.1 \pm 0.10$)$ recorded in April respectively. Whereas, the lowest number of collectied flies was observed in January for both $B$. zonata $(3.23 \pm 0.41)$ and $B$. dorsalis (0.33 \pm 0.19$)$. During, February, the population of $B$. zonata and $B$. dorsalis was $11.89 \pm 0.89$ and 2.21 \pm 0.40 , respectively; while in March mean counts for B. zonata and $B$. dorsalis were $15.41 \pm 1.10$ and $5.40 \pm 0.54$, respectively. Accordingly, it was observed in the study that population captured in various treatments showed an increasing trend with time elapse, as the highest population of both species was recorded during April. The prominent difference in the fly collection between January and April can be attributed to the temperature and humidity. The similar results have also been reported previously by different researchers [29-32].

The data for each treatment (Table 1) demonstrate that, the lemon essence was most effective to attract both species. In the month of January, the highest mean number of $B$. zonata were collected at the traps

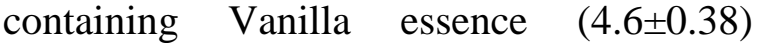
followed by lemon $(3.66 \pm 0.51)$, orange (2.91 \pm 0.28$)$, control $(2.75 \pm 0.42)$ and lastly mango essence $(2.66 \pm 0.44)$. However, there was no significant difference observed between all the treatments. Moreover, in January the mean number of $B$. dorsalis was $0.00 \pm 0.00,0.25 \pm 0.17,0.66 \pm 0.30,0.33 \pm 0.25$, $0.41 \pm 0.22$ in traps impregnated with lemon essence, mango essence, vanilla essence, orange essence and control. In subsequent months (February, March and April), the highest number of fruit flies were trapped in traps baited with lemon essence for B. zonata and $B$. dorsalis. The mean number of recorded population was 17.5 \pm 1.03 (February), 21.81 \pm 1.42 (March) and $272.75 \pm 12.62$ (April) for B. zonata. Whereas, in case of $B$. dorsalis, the captured flies were $3.25 \pm 0.45,9.43 \pm 0.65$ and $18.30 \pm 0.84$ for the months of February, March and April, respectively. These statistical number are highly significant $(p=0.02)$ than other treatments. The grand mean of treatments (Figure 1) showed that lemon essence was most efficient trap against both the fruit fly species whereas, control trap was least productive. The manipulation of baits to attract more fruit fly species was practiced by many workers to improve the efficacy of traps. The variations are reported by John and coworkers [33] Casana [34] and Victor et al. [24] which confirms that manipulation of 
baits can increase the attraction of flies. The observations of this study are also in agreement with work published previously. The use of different essences in combination of methyl eugenol is formerly reported by Ullah and colleagues [26]. They have conducted the experiments in peach orchards and found promising results which is in accordance with the results obtained in this study.

Impact of abiotic factors on trapping performance of treatments

The data in (Table 2) shows that there was positive relationship between temperature and trapped number of the $B$. zonata and $B$. dorsalis. The $\mathrm{r}$ value of correlation was 0.7818, 0.7798, $0.7745,0.7748$ and 0.7698 for lemon essence, mango essence, vanilla essence, orange essence and control, respectively, for $B$. zonata. Concurrently, the $\mathrm{r}$ value in case of $B$. dorsalis for each treatment was 0.9219 (lemon essence), 0.8958 (mango essence), 0.8595 (vanilla essence), 0.7896 (orange essence) and 0.8424 (control).

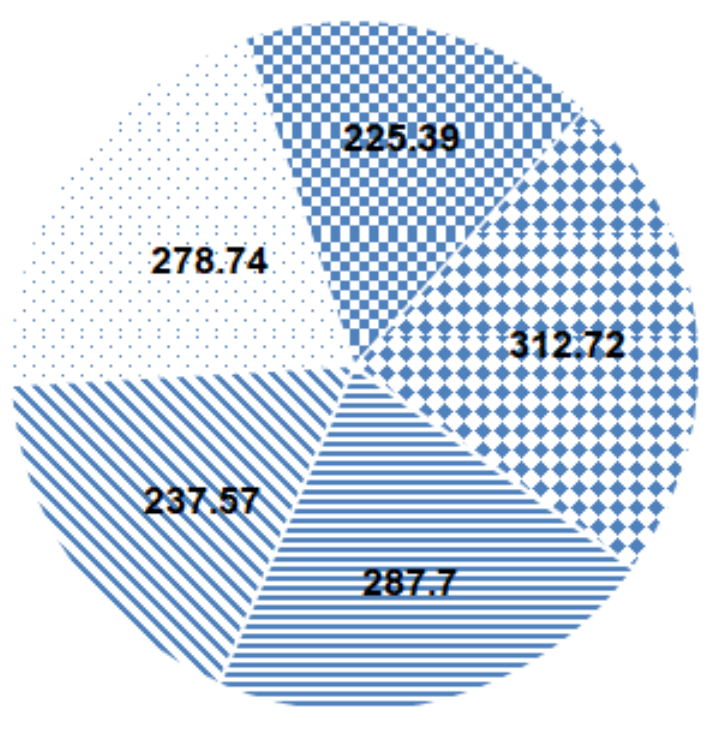

A) Grand mean of B. zonata

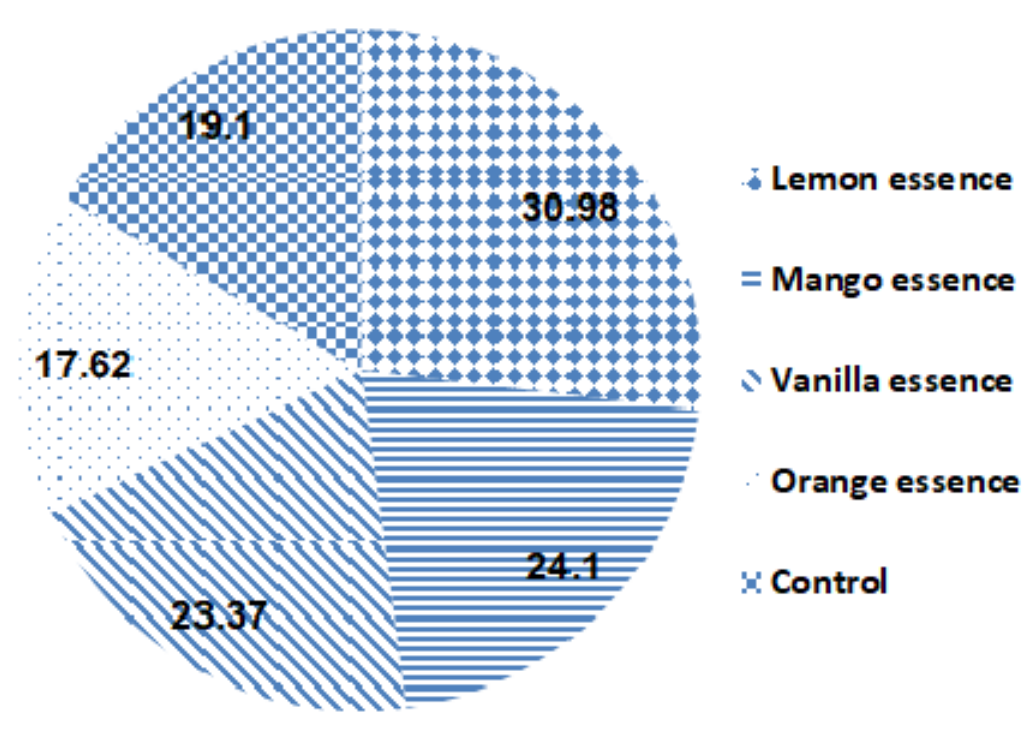

B) Grand mean of $B$. dorsalis

Figure 1. Grand mean of Bactrocera zonata and Bactrocera dorsalis captured during the study period at each treatment 
Table 1. Mean number of male Bactrocera zonata and Bactrocera dorsalis trapped in different bait traps

\begin{tabular}{|c|c|c|c|c|c|c|c|c|}
\hline \multirow{2}{*}{ Treatments } & \multicolumn{4}{|c|}{ Bactrocera zonata } & \multicolumn{4}{|c|}{ Bactrocera dorsalis } \\
\hline & January & February & March & April & January & February & March & April \\
\hline Lemon essence & $3.66 \pm 0.51^{\mathrm{a}}$ & $17.5 \pm 1.03^{\mathrm{a}}$ & $21.81 \pm 1.42^{\mathrm{a}}$ & $272.75 \pm 12.62^{a}$ & $0.00 \pm 0.00 \mathrm{a}$ & $3.25 \pm 0.45^{\mathrm{a}}$ & $9.43 \pm 0.65^{\mathrm{a}}$ & $18.30 \pm 0.84^{\mathrm{a}}$ \\
\hline Mango essence & $2.66 \pm 0.44^{\mathrm{a}}$ & $10.6 \pm 0.87^{b c}$ & $18.69 \pm 1.30^{\mathrm{ab}}$ & $255.75 \pm 9.51^{\mathrm{b}}$ & $0.25 \pm 0.17 \mathrm{a}$ & $2.12 \pm 0.43^{\mathrm{abc}}$ & $7.43 \pm 0.74^{\mathrm{a}}$ & $14.30 \pm 1.04^{\mathrm{b}}$ \\
\hline Vanilla essence & $4.6 \pm 0.38^{\mathrm{a}}$ & $12.6 \pm 0.99^{b}$ & $13.87 \pm 1.19^{c}$ & $207.50 \pm 11.61^{\mathrm{c}}$ & $0.66 \pm 0.30 \mathrm{a}$ & $3.06 \pm 0.62^{\mathrm{ab}}$ & $4.50 \pm 0.74^{\mathrm{b}}$ & $15.15 \pm 1.02^{\mathrm{ab}}$ \\
\hline Orange essence & $2.91 \pm 0.28^{\mathrm{a}}$ & $9.06 \pm 0.74^{\mathrm{c}}$ & $14.12 \pm 0.95^{\mathrm{bc}}$ & $252.65 \pm 8.84^{\mathrm{b}}$ & $0.33 \pm 0.25 \mathrm{a}$ & $1.18 \pm 0.20^{\mathrm{c}}$ & $2.06 \pm 0.21^{\mathrm{c}}$ & $14.05 \pm 0.98^{b}$ \\
\hline Control & $2.75 \pm 0.42^{\mathrm{a}}$ & $9.18 \pm 0.72^{b c}$ & $8.56 \pm 1.11^{\mathrm{d}}$ & $204.90 \pm 9.22^{\mathrm{c}}$ & $0.41 \pm 0.22 \mathrm{a}$ & $1.43 \pm 0.30^{\mathrm{bc}}$ & $3.56 \pm 0.36^{\mathrm{bc}}$ & $13.70 \pm 1.11^{\mathrm{b}}$ \\
\hline Total mean & $3.23 \pm 0.41$ & $11.89 \pm 0.89$ & $15.41 \pm 1.10$ & $238.81 \pm 11.39$ & $0.33 \pm 0.19$ & $2.21 \pm 0.40$ & $5.40 \pm 0.54$ & $15.1 \pm 0.10$ \\
\hline
\end{tabular}

Note: The symbol * shows the significance impact of abiotic factors

*For each species, the means with same small letters in the same row are not significantly different

Table 2. Correlation of Male Bactrocera zonata and Bactrocera dorsalis captured in different treatments with environmental factors

\begin{tabular}{|c|c|c|c|c|c|c|c|c|c|c|}
\hline \multirow{2}{*}{$\begin{array}{c}\text { Environmental } \\
\text { Factor }\end{array}$} & \multicolumn{5}{|c|}{ Bactrocera zonata } & \multicolumn{5}{|c|}{ Bactrocera dorsalis } \\
\hline & $\begin{array}{l}\text { Lemon } \\
\text { essence }\end{array}$ & $\begin{array}{l}\text { Mango } \\
\text { essence }\end{array}$ & $\begin{array}{l}\text { Vanilla } \\
\text { essence }\end{array}$ & $\begin{array}{l}\text { Orange } \\
\text { essence }\end{array}$ & Control & $\begin{array}{l}\text { Lemon } \\
\text { essence }\end{array}$ & $\begin{array}{l}\text { Mango } \\
\text { essence }\end{array}$ & $\begin{array}{l}\text { Vanilla } \\
\text { essence }\end{array}$ & $\begin{array}{l}\text { Orange } \\
\text { essence }\end{array}$ & Control \\
\hline \multirow{2}{*}{ Temperature } & 0.7818 & 0.7798 & 0.7745 & 0.7748 & 0.7698 & 0.9219 & 0.8958 & 0.8595 & 0.7896 & 0.8424 \\
\hline & $0.0003^{*}$ & $0.0004^{*}$ & $0.0004 *$ & $0.0004^{*}$ & $0.0005^{*}$ & $<.0001 *$ & $<.0001^{*}$ & $<.0001^{*}$ & $0.0003^{*}$ & $<.0001^{*}$ \\
\hline \multirow{2}{*}{ Humidity } & -0.4462 & -0.4457 & -0.4395 & -0.4346 & -0.4265 & -0.6413 & -0.6180 & -0.5434 & -0.4629 & -0.4870 \\
\hline & 0.0832 & 0.0836 & 0.0885 & 0.0925 & 0.0994 & $0.0074 *$ & $0.0107 *$ & $0.0296^{*}$ & 0.0710 & 0.0557 \\
\hline
\end{tabular}

Note: The numbers donated with $*$ shows significant effect of abiotic factors. 
Furthermore, the effect of temperature was significant on the increase of population in each treatment because as the temperature increases, the numbers of catches also increases. On contrary, the humidity had negative impact on the collection of flies in each trap. The $r$ values for each treatment; lemon essence, mango essence, vanilla essence, orange essence and control were $0.4462,-0.4457,-0.4395,-0.4346$ and 0.4265 for $B$. zonata. In case of $B$. dorsalis, the $r$ values were $-0.6413,-0.6180,-0.5434$, 0.4629 and -0.4870 for lemon essence, mango essence, vanilla essence, orange essence and control, respectively. Form the literature published previously, the results of this particular study are in agreements. For instance, Kannan and Venugopala [35] in 2006, Mahmood and Mishkatullah in 2007 [36] and Laskar and Chatterjee [37] in 2010 proved in their studies there is significant impact of environmental factor on the population of fruit flies. They also observed positive impact of temperature on fruit flies population and negative relationship with humidity. The increase in catches of flies with increment in temperature may be because of biology of the pests. The most of the eggs of fruit flies do not hatch at or above $40{ }^{\circ} \mathrm{C}$ and at or temperature below $12.5^{\circ} \mathrm{C}$. Moreover the incubation period at $35^{\circ} \mathrm{C}$ is as short as 3.2 days whereas at $15.0^{\circ} \mathrm{C}$ is may take 35 days to hatch [38]. Therefore, this study also indicated that the in the month of April when temperature become favourable for the fruit flies more catches were observed.

\section{Conclusion}

The observations of the study can be concluded that there is significant impact of adding essences of different fruits to traps of $\mathrm{ME}$ in order to increase their performance on attraction of both species of fruit flies. Further studies may also be conducted to check other materials to improve the Male annihilation technique. Moreover, the detail study on effect of abiotic factors on dispersal and coverage area of essences can be conducted.

\section{Authors' contributions}

Conceived and designed the experiments: FN Khoso \& IA Nizamani, Performed the experiments: MA Chajro \& FN Khoso, Analyzed the data: JD Hjano \& AM Lodhi, Contributed materials/ analysis/ tools:, M Ahmed \& A Ali, Wrote the paper: FN Khoso, I Khatri \& S Otho.

\section{References}

1. Anonymous (2011). Agricultural Statistics of Pakistan, 2010-2011. Ministry of Food, Agriculture and Cooperatives. Govt. of Pakistan, Islamabad, Pakistan.

2. Bhatti AG, Ismail NJ, lodhi AM \& Maitlo WA (2011). Isolation and identification causing deteriotion of guava (Psidium guajava) L.) in Larkana, Sindh. In: Abstracts "Challenges and Options for Plant Health Management", $8^{\text {th }}$ National Conference of Pakistan Phytopathological Society, 28-29 November 2011, University of Agriculture, Faisalabad, Pakistan, pp 64.

3. Panhwar F (2005). Genetically evolved guava (Psidium gujava) and its future in Pakistan. Chemlin. 1-7.

4. Yan LY, Teng LT \& Jhi TJ (2006). Antioxidant Properties of Guava Fruit: Comparison with Some Local Fruits. Sunway Acad J 3: 9-20.

5. Bal JS \& Dhaliwal GS (2004). Distribution and quality characteristics of graded guava fruits. Haryana J Hort Sci 33: 53-54.

6. Rahman H, Khokhar KM, Khan MA \& Ahmed M (1990). Guava: State and art of production technology prog, Farm, 10: 20-30.

7. Baradi EI (1975).Tropical fruits Psidium guajava. Abstracts on Tropical Agriculture 1: 16.

8. Aliyu HM (2006). Proximate analysis of some leafy vegetables (Roselle, Jute and Bitter leaf). Int J Agri Food Res 3(1): 1114.

9. Begum S, Hassan SI \& Siddiqui BS (2002). Two new triterpenoids from the 
fresh leaves of Psidium guajava. Planta Med 68: 1149-1152.

10. Belemtougri RG, Constantin B, Cognard C, Raymond G \& Sawadogo L (2006). Effects of two medicinal plants Psidium guajava L. (Myrtaceae) and Diospyros mespiliformis L. (Ebenaceae) leaf extracts on rat skeletal muscle cells in primary culture. J Zhejiang Univ Sci B 7(1): 56-63.

11. Jaiarj P, Khoohaswan P, Wongkrajang Y, Peungvicha P, Suriyawong P, Saraya MLS \& Ruangsomboon O (1999). Anticough and antimicrobial activities of Psidium guajava L. Leaf extract. J Ethnopharmacol 67 (2): 203-212.

12. Sarwar M (2006). Occurrence of Insect Pests on Guava (Psidium guajava) Tree Pakistan. J Zool 38(3): 197-200.

13. White IM \& Elson-Harris MM (1992). Fruit Flies of Economic Significance: Their Identification and Bionomics; CABI International: Wallingford, UK.

14. Anonymous (2015). Dacine Fruit Flies of the Asia-Pacific. http://www.herbarium.hawaii.edu/fruitfl $\mathrm{y} /$.

15. Vargas RI, Pinero JC \& Leblanc L (2015). An overview of pest species of Bactrocera fruit flies (dipteral; tephritidae) and the integration of biopesticides with other biological approaches for their management with a focus on the pacific region. Insects 6 : 297-318.

16. Syed RA, Ghani MA \& Murtaza M (1970). Studies on the tephritids and their natural enemies in West Pakistan. III. Dacus zonatus (Saunders). Technical Bulletin, Commonwealth Institute of Biol Control 1-16.

17. Abbasi QD, Hussain T, Talpur MA, Ahmed M, Shakoori AR \& Memon M (1992). Efficacy of different insecticides in controlling ber fruit fly, Carpomyia vesuviana Costa. Proc Pakistan Congr Zool 12: 357-361.
18. Mahmood Z, Ullah F \& Iqbal M. (1995). Efficacy of various insecticides used in pheromone traps for the control of oriental fruit fly, Bactrocera dorsalis (Diptera: Tephritidae) in Bannu (Khyber Pakhtunkhwa), Pakistan. Sarhad J Agric 11(2): 181-187.

19. Saikia DK \& Dutta KS (1997). Efficacy of some insecticides and plant products against fruit fly, Dacus tau (Walker) on ridge gourd, Luffaa cutangula L. J Agric Sci 10(1): 132-135.

20. Singh S, Gupta RN, Awasthi BJ, Verma RA, \& Singh S (2000). Effective control of ber fruit fly, Carpomyia vesuviana by insecticidal schedule. Indian J Ent 62(2): 171-174.

21. Clark RA, Steek LG \& Weems VH (1996). Detection, quarantine, and eradication of exotic fruit flies in Florida, In Pest management in subtropics Florida perspective. Intercept, Andover, UK. 29-54.

22. Chuang YY \& Hou FR (2008). Effectiveness of attract-and-kill systems using methyl eugenol incorporated with neonicotinoid insecticides against the oriental fruit fly (Diptera: Tephritidae). $J$ Econ Entomol 101(2): 352-359.

23. Afia YE (2007). Comparative studies on the biology and ecology of the two fruit flies, in Egypt Bactrocera zonata (Saunders) and Ceratitis capitata (Wiedemann). Ph. D. Thesis, Cairo University.

24. Victor RC, Martin G, Rene A \& Patricia V (2004). Two low Cost Food Attractant for Capturing Toxolrypana curvicauda (Diptera: Tephritidae) in the Field. $J$ Econ Entomol 97(2): 310-315.

25. Fabre F, Ryckewaert P, Duyck FP, Chiroleu F \& Quilicf S (2003). Comparison of the efficacy of different food attractant and their concentration for melon fly (Diptera: Tephritidae). $J$ Econ Entomol 96(1): 231-232.

26. Ullah F, Rehman U, Wardak $H$, Badshah, Ahmad A \& Kakar MQ 
(2015). Response of male fruit fly (Diptera: tephritidae) to various food essences in methyl eugenol and cue-lure baited traps. J Entomol Zool 3 (5): 239245.

27. Bugti NK, Bashir W, Baloch AQ, Sattar A, Ahmed M, Noor H, Reki MT, Kethran R, Ahmed S, Shawani AR \& Ruk AS (2015). Population dynamics of fruit flies on different varieties of Jujube. J Bio Agri Heal 5(21): 150-156.

28. Prabhakar CS, Pankaj S \& Mehta PK (2012). Pictorial keys for predominant Bactrocera and Dacus fruit flies (Diptera: Tephritidae) of north western Himalaya. Arthropods 1(3): 101-111.

29. Divender G, \& Bhatia R (2000). Population fluctuations of fruit flies, Bactrocera spp. in sub mountainous mango and guava orchards. J Appl Hort 2(1): 47-49.

30. Vargas RI, Miller WN \& Stark DJ (2003). Field trials of spinosad as a replacement for Naled, DDVP, and Malathion in Methyl Eugenol and CueLure bucket traps to attract and kill male Oriental fruit flies and melon flies (Diptera: Tephritidae) in Hawaii. J Econ Entomol 96(6):1780-1785.

31. Ye H \& Liu J (2007). Population dynamics of oriental fruit fly Bactrocera dorsalis (Diptera: Tephritidae) in Xishuangbanna, Yunnan Province China. Front Agric China 1: 76-80.

32. Ahmad U, \& Begum U (2017). A weekly study on Bactrocera zonata S. and Bactrocera dorsalis H. (Diptera: Tephritidae) against methyl eugenol, raspberry essence and GF-120 in persimmon orchards from Kohat, Pakistan. Indian J Agric Res 51(2): 176179.

33. John S, Afzal M, Qamar A, Mumford J, Poswal A \& Mahmood R (2001). Single -Killing-Point field assessment of bait and lure control of fruit flies (Diptera: Tephritidae) in Pakistan. J Crop Prot 1(8): 651-659.

34. Casana GV, Oliver JE, Jang E \& Carvalho L (2003). Syntheses and behavioral evaluations of fluorinated and silylated analogs of raspberry ketone as attractants for the melon fly, Bactrocera cucurbitae (Coquillett). J Entomol Sci 38(1):111-119.

35. Mahmood K, \& Mishkatullah, (2007) Population Dynamics of Three Species of Genus Bactrocera (Diptera: Tephritidae: Dacinae) in BARI, Chakwal (Punjab). Pakistan J. Zool 39(2): 123126.

36. Kannan M \& Venugopala N (2006). Ecological studies on Mango fruit fly, Bactrocera dorsalis Handel. Ann Plant Protect Sci 14(2): 340-342.

37. Laskar, N. and H. Chatterjee. 2010. The Effect of Meteorological Factors on the Population Dynamics of Melon fly, Bactrocera cucurbitae (Coq.) (Diptera: Tephritidae) in the foot hills of Himalaya. J Appl sci envir manag 14(3): 53-58.

38. Imura O \& Nakakita H (2003). The effect of temperature and relative humidity on the development of Tribolium freemani Hinton (Coleoptera: Tenebrionidae). $J$ Stored Prod Res 20(2): 87-95. 